\title{
SEISMIC BEHAVIOR OF THROUGH-DIAPHRAGM CONNECTIONS BETWEEN CFRT COLUMNS AND STEEL BEAMS-EXPERIMENTAL STUDY
}

\author{
Ying Qin ${ }^{1}$, Zhihua Chen ${ }^{2, *}$, Xiaodun Wang ${ }^{3}$ and Ting Zhou ${ }^{4}$ \\ ${ }^{1}$ Graduate Research Assistant, Department of Civil Engineering, Tianjin University, Tianjin, China, and Visiting \\ Research Scholar, Department of Civil Engineering, Johns Hopkins University, Baltimore, MD, USA \\ ${ }^{2}$ Professor, Key Laboratory of Coast Civil Structure Safety of China Ministry of Education, Tianjin University, \\ Tianjin, China, and Department of Civil Engineering, Tianjin University, Tianjin, China \\ ${ }^{3}$ Associate Professor, Department of Civil Engineering, Tianjin University, Tianjin, China \\ ${ }^{4}$ PhD, Department of Civil Engineering, Tianjin University, Tianjin, China \\ *(Corresponding author: E-mail: zhchen@tju.edu.cn)
}

Received: 1 August 2013; Revised: 18 September 2013; Accepted: 23 September 2013

\begin{abstract}
This paper is an extension study to an experimental program involving one traditional and three novel through-diaphragm connections between concrete-filled rectangular tubular columns and steel H-beams. The proposed connection types utilize tapered diaphragm or triangular plates at the end of the beam to improve the seismic performance of traditional through-diaphragm connections. Based on the experimental results, the lateral force versus beam-column deformation response was assessed and the shear force versus shear distortion relationship in the panel zone was evaluated. It was observed that the improvement in connection details significantly enhanced the rotation capacity and shear stiffness. The deformation of the connections was also analyzed in terms of the contribution of the column, the beam, and the joint. In addition, the force transfer mechanism in the connections was investigated by analysis of the strain distribution The test results indicate that the proposed through-diaphragm connections are able to alleviate the stress concentration in the load transfer path and exhibit better seismic behavior. As a result, it can be concluded that the proposed connections are more suitable for applications in moment resisting frames in seismic regions.
\end{abstract}

Keywords: Through-diaphragm connections, Concrete-filled rectangular tubular column, Seismic performance, Experimental behavior, Strain distribution

\section{INTRODUCTION}

Concrete-filled rectangular tubular (CFRT) columns have been widely used in practical applications these days due to their benefits of excellent mechanical behavior and architecturally pleasing advantages.

A large amount of research has been conducted on the connections between CFRT columns and steel H-beams. Previous investigation on the experimental behavior of H-beam-to-CFST column connections has included that of Kang et al. [1], Varma et al. [2], Ricles et al. [3], Shin et al. [4], Cheng et al. [5], Wu et al. [6], Nie et al. [7], Wang et al [8], Park et al. [9], and Qin et al. [10-11]. Theoretical study on the flexural strength and shear strength has been conducted by Kawano et al. [12], Koester [13], Lu et al. [14], Morino et al. [15], Fukumoto et al. [16], Park et al. [17], Jiang et al. [18], Nie et al. [19], Rong et al. [20], and Qin et al. [21-23]. Additionally, various connection alternatives have been proposed and explored by researchers, such as the application of blind bolt [24-26], combined channel angle connections [27], and through-bolt connections [28]. Damage assessment [29], computationally performance simulation [30], and design approach investigation [31] represent other areas of interest. Several state-of-the-art reports and papers also presented a large number of research results on CFRT column-to-H-beam connections [32-36]. 
However, few studies have considered the improvement of the through-diaphragm connections or the seismic behavior of the panel zone. As a part of investigations on the seismic behavior of CFRT connections, in this research, one traditional and three improved through-diaphragm specimens were tested to evaluate the seismic performance of the connections subjected to cyclic loading. The experimental results including moment-rotation response, strength and stiffness degradation, ductility, drift rotation and energy dissipation have been presented in a parallel paper [10]. An extension to this work which considers the behavior of panel zone, the deformation, and the force transfer mechanism is described here.

\section{CFRT CONNECTIONS}

\subsection{Traditional Connection Types}

Three conventional connections are currently used for CFRT column moment resisting frame (MRF) system in some Asian countries such as China, Japan and Korea [37]. As shown in Figure 1, each employs an internal diaphragm, an external diaphragm, or a through diaphragm.

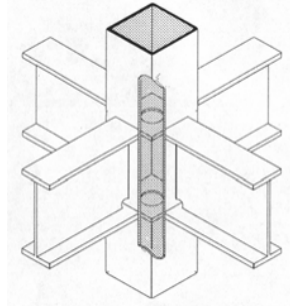

(a) Internal diaphragm

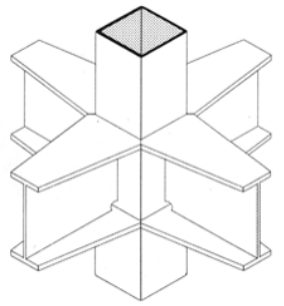

(b) External diaphragm

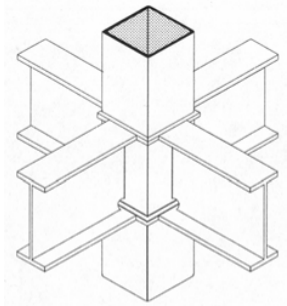

(c) Through diaphragm

Figure 1. Conventional Details of Connections to CFRT Columns

The internal diaphragm connection is made by inserting the diaphragm into the steel tube and connecting the beam flanges to the tube surface, as shown in Figure 1(a). It has the merit of not interfering with the finishing materials outside the column. However, necessary measures should be taken when infilling concrete into the steel tubes, in order to prevent the occurrence of voids under the diaphragm. In this case, the tensile force transferred from beam flanges is directly delivered to column flanges. Since the internal diaphragm is welded around its perimeter to the steel tube and the steel tube column restrains the deformation of the diaphragm, most of the deformation in the panel zone is concentrated along the direction of the thickness of the column flanges. When the tensile force is large enough, the failure of the connections may accompany punching shear, which induces the fracture of the weld between the beam flanges and column flanges. Additionally, lamellar tearing of the column flange may occur at the same time. This failure mode was observed in the simple tension test and cyclic loading test conducted by Choi et al. [38], as shown in Figure 2(a). 
The external diaphragm connection detail, as shown in Figure 1(b), attaches the diaphragm to the outside of the steel tube and needs no cutting of steel tube for fabrication. However, the external diaphragm lacks aesthetics and may have limitations on the size of the diaphragm for a joint of an exterior frame. Due to the abrupt change of the cross-sectional area between the beam flange and external diaphragm, the stress and deformation concentration there causes the failure of groove weld [39].

The detail of through diaphragm connection, as shown in Figure 1(c), requires diaphragms penetrating the steel tube and beam flanges directly welding to the through diaphragm. In this case, the tensile force is transferred from the beam flanges to the through diaphragm. This detail significantly moves the plastic hinge away from the steel tube surface and smooth the load transfer path, although it involves much on-site welding and imposes construction complication. The failure of connections is often caused by the crack developed in the groove weld between beam flanges and through diaphragm, as shown in Figure 2(b) [38].

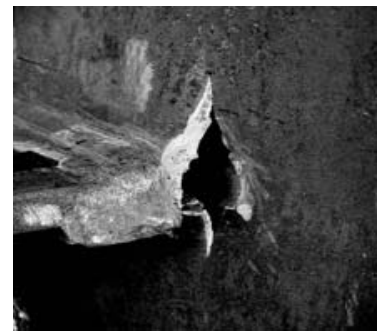

(a) Internal diaphragm

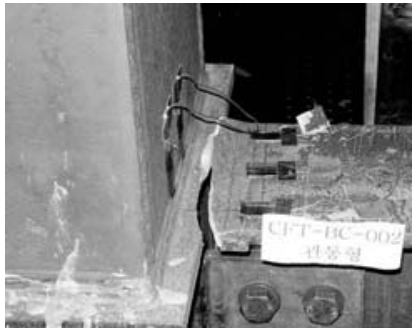

(b) Through diaphragm

Figure 2. Example of Connection Failure

\subsection{Proposed Connections with through Diaphragm}

To avoid the abrupt change of cross section between the beam flanges and through diaphragm and reduce the stress concentration there, three improved through-diaphragm connection details were studied herein. Specimen JD-2 had a tapered diaphragm with an extended length of 320mm, as illustrated in Figure 3(b). In Specimen JD-3 and JD-4, the through-diaphragm penetrated the steel tube and extended a length of $20 \mathrm{~mm}$. Horizontal haunches were attached to the beam flange to form the tapered flange at the beam end as shown in Figure 3(c) and (d). These details were both designed to transfer the tension force from the beam flange directly to the sides of the steel tube and provide a more gradual transition in the geometry of the connection region. The weld access hole shown in Figure 4(a) was used in specimen JD-1 and JD-2, while that in Figure 4(b) was used for specimen JD-3 and JD-4. A more detailed description on the specimen design can be found in [10]. 


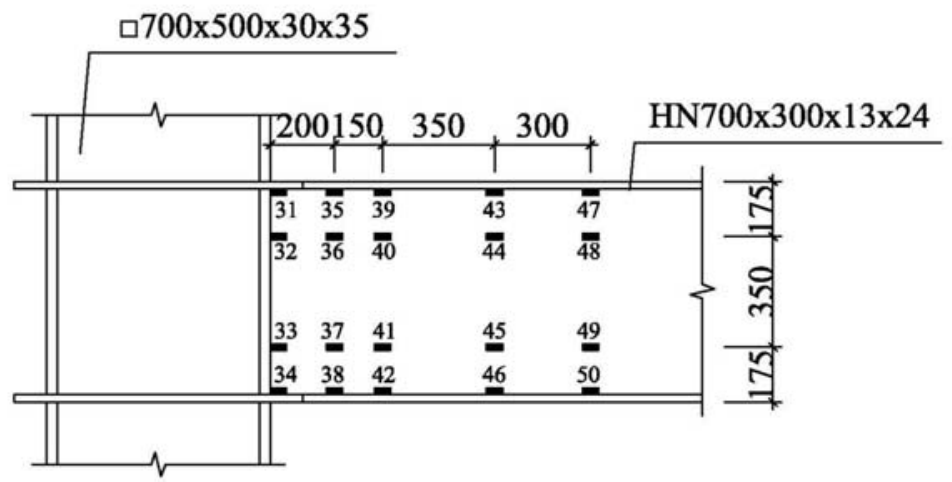

Web

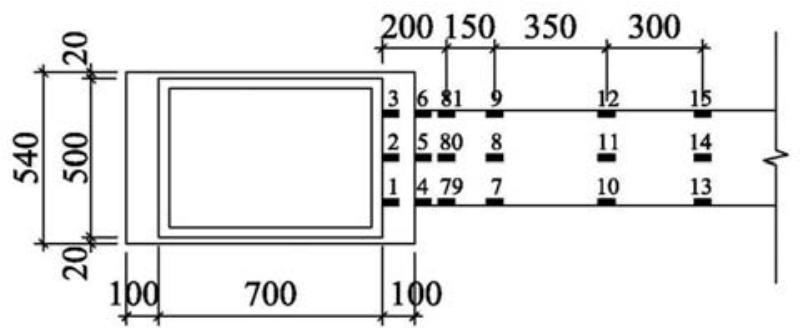

Top flange

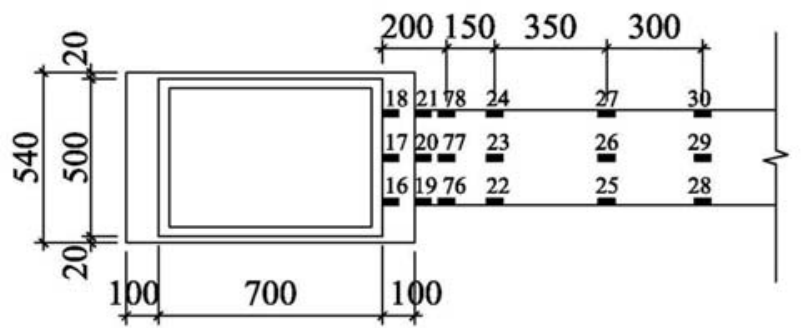

Bottom flange

(a) Specimen JD-1 


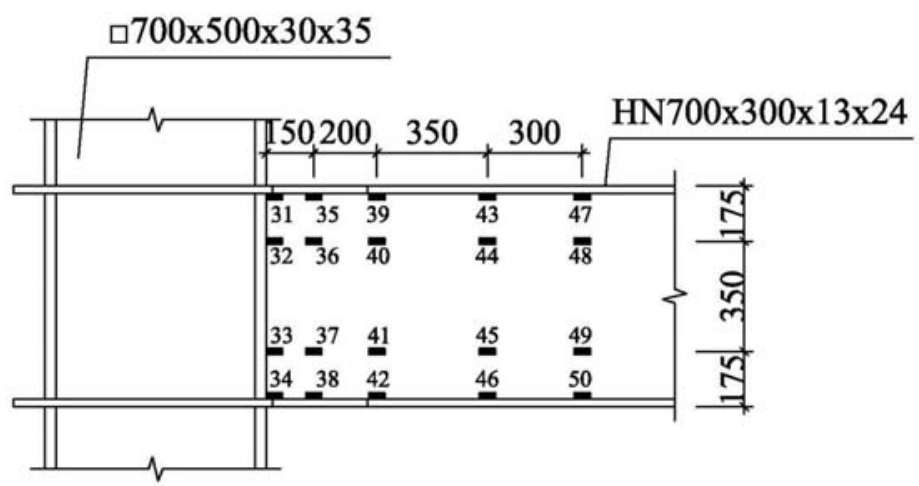

Web

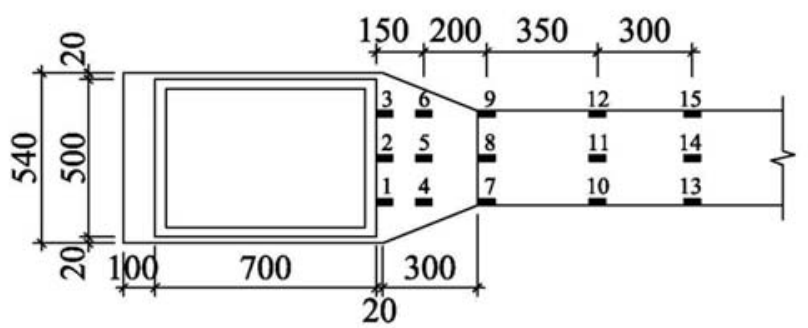

Top flange

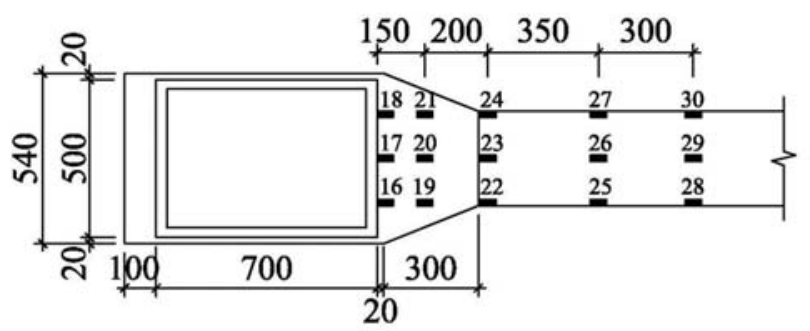

Bottom flange

(b) Specimen JD-2 


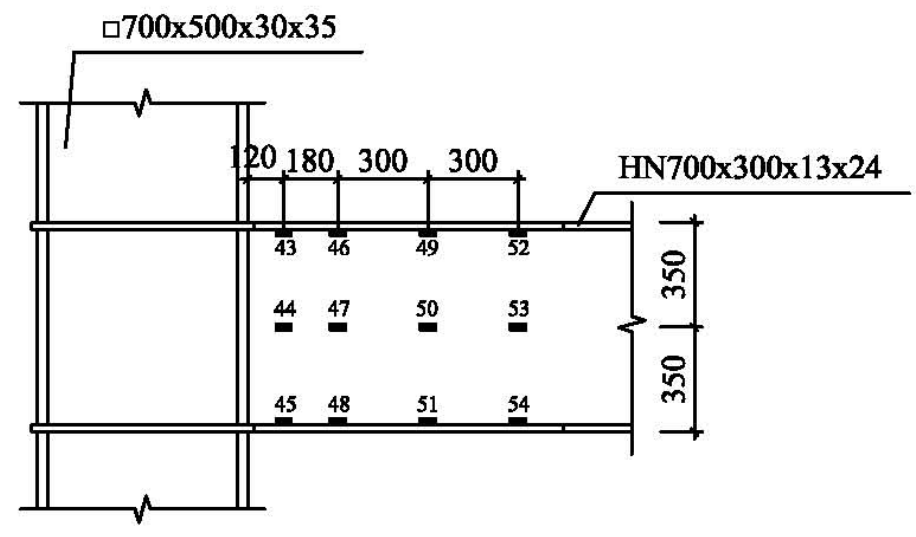

Web

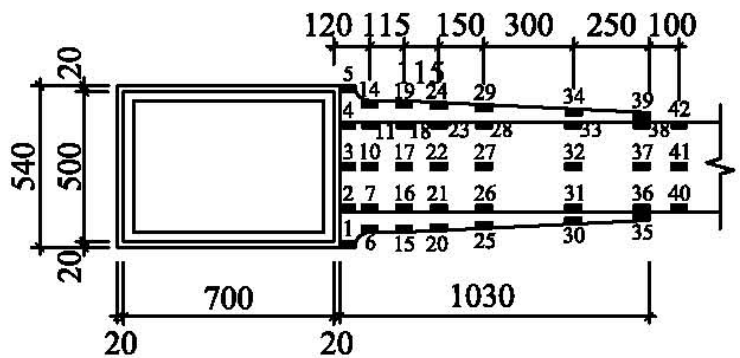

Top flange
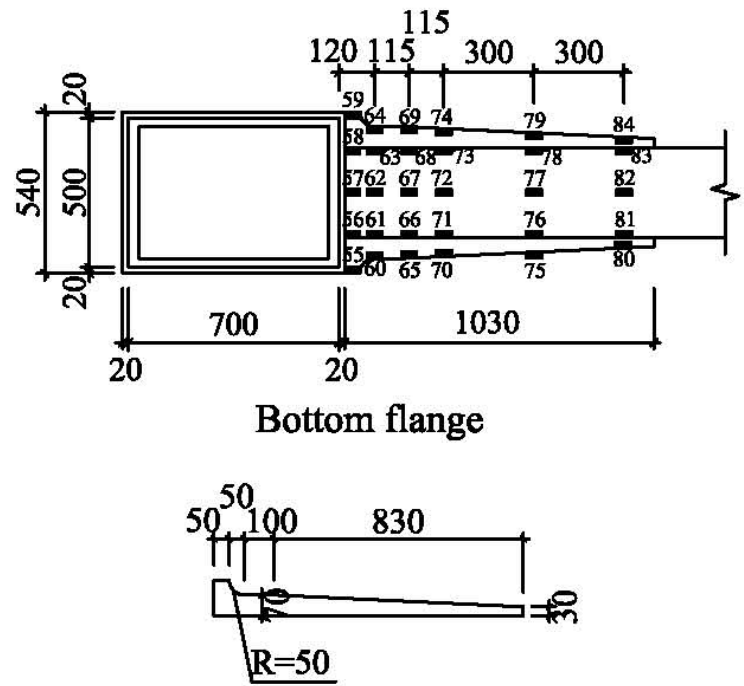

Horizontal haunch detail

(c) Specimen JD-3 


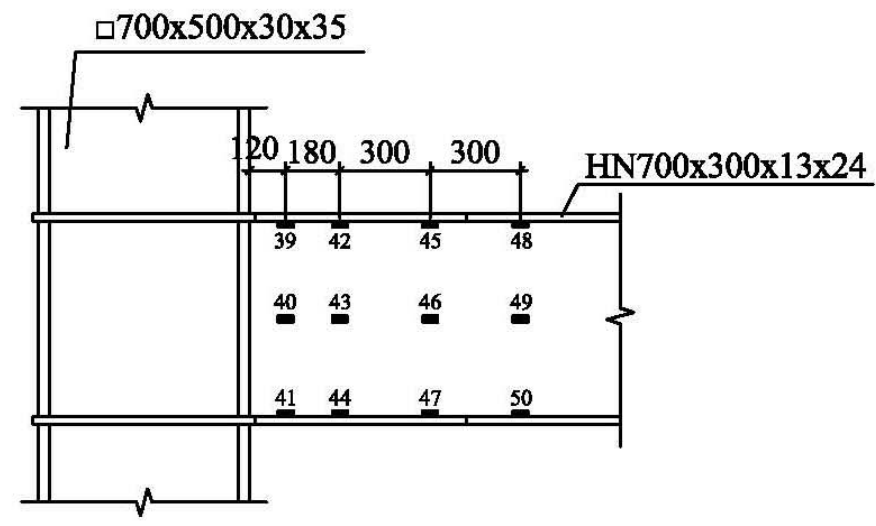

Web

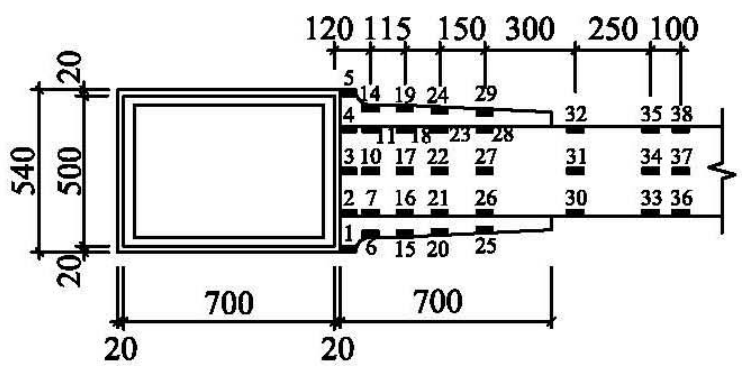

Top flange
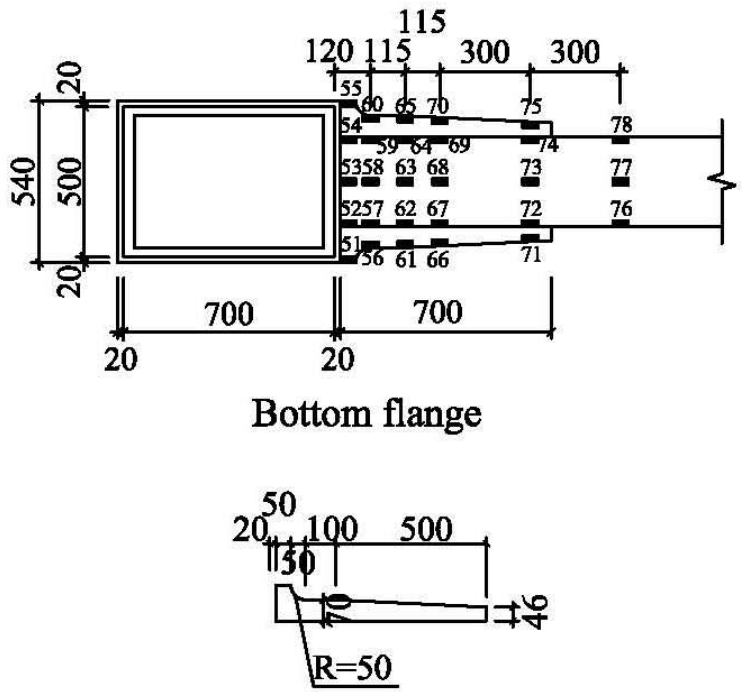

Horizontal haunch detail

(d) Specimen JD-4

Figure 3. Details of Specimens and Layout of Strain Gauge 


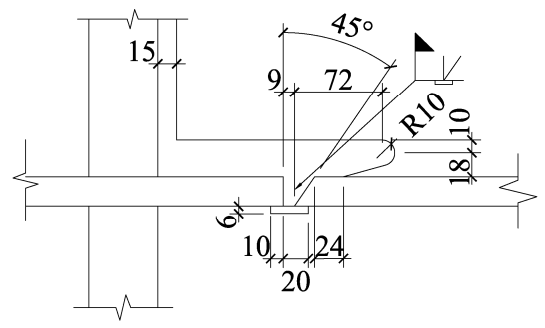

(a) Type 1



(b) Type 2

Figure 4. Weld Access Hole

\section{EXPERIMENTAL PROGRAM AND TEST RESULTS}

\subsection{Experimental Program}

The test specimens were constructed in a tee shape to simulate the external connection of a steel MRF with a height of $4.2 \mathrm{~m}$ and a bay width of $7.2 \mathrm{~m}$. Four full-scale beam-to-column connections were tested under quasi-static cyclic loading to study the hysteretic behavior of the existing and proposed through-diaphragm connections to CFRT columns. The geometric detail of the connections and the test setup are given in Figures 3 and 5, respectively. The pin boundary condition was created where the inflection points were assumed. The horizontal cyclic loading was applied to the specimen by an actuator bolted to the reaction wall. The lateral loading procedure of the specimens was generally according to recommendations provided by ANSI/AISC 341-10 [40]. The layout of the displacement transducers is illustrated in Figure 6. The detailed description of the test program is described in the parallel paper [10].
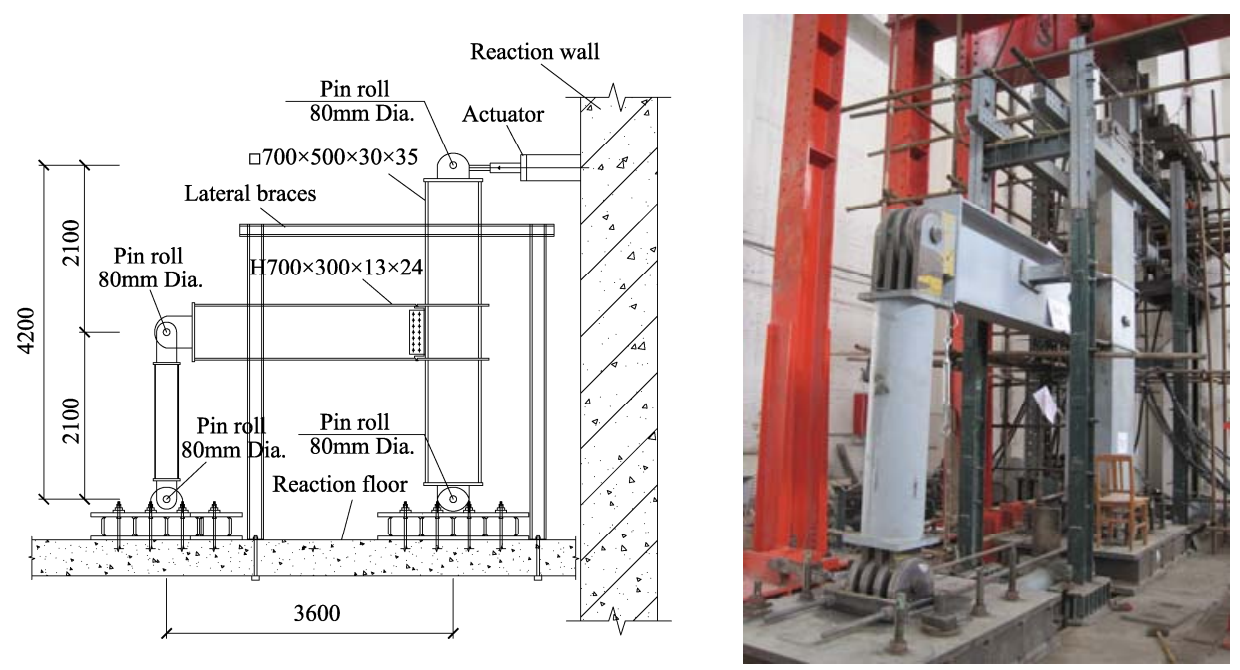

Figure 5. Test Setup 




Figure 6. Arrangement of Displacement Transducers

\subsection{Lateral Force Versus Beam-Column Deformation Relationship}

The lateral load versus beam-column deformation relationship is one of the principal ways of assessing the seismic behavior of the connection. The force-deformation curves are shown in Figure 7, in which force is the horizontal load applied to the top of the column and deformation is the rotational angle of the beam-column measured by displacement transducer 3 and 4, as shown in Figure 6.

It can be seen that the hysteresis loops of all the specimens are in a shuttle shape, stable, plentiful and energy dissipative. A ductile behavior is developed as the number of cycle increases and the cyclic loading process continues. No obvious strength or stiffness degradation is observed in the test. As a consequence, the specimens exhibit satisfactory seismic performance. Meanwhile, it is observed that the hysteresis behavior of proposed connections (Specimen JD-2-JD-4) achieved a higher rotation capacity compared to the traditional through-diaphragm connection (Specimen JD-1). This enhanced behavior is attributed to the additional seismic resistance that is provided by the tapered diaphragm or the triangular plates at the end of the steel beam.

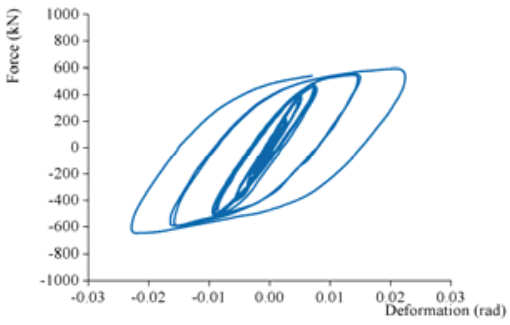

(a) Specimen JD-1

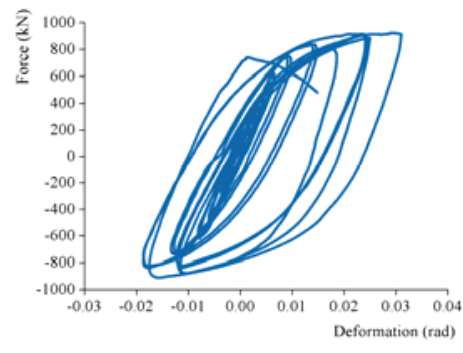

(c) Specimen JD-3

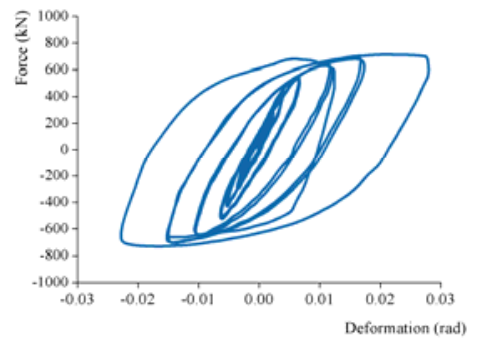

(b) Specimen JD-2

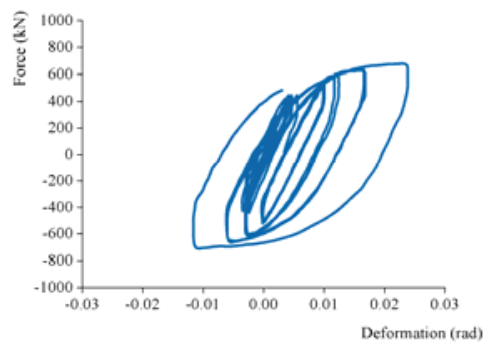

(d) Specimen JD-4

Figure 7. Lateral Force Versus Beam-column Deformation Curves 


\section{3 $Q_{j}-\gamma_{j}$ Curves}

Regarding through-diaphragm connections, the cyclic behavior is governed by the panel zone and/or by the beam end. Considering the strengthening and stiffening effect of through-diaphragm, the cyclic response of the connections is given by the cyclic shear behavior of the panel zone, by the cyclic bending behavior of the connected steel beam, or by a combination of both [40]. In order to evaluate the performance of the panel zone of the connection, $Q_{j}-\gamma_{j}$ hysteresis loops of the specimens are shown in Figure 9. $Q_{j}$ is the shear force in the panel zone, $\gamma_{j}$ is the shear deformation in the panel zone as shown in Figure 8 and can be determined by Eq. 1.

$\gamma_{j}=\frac{1}{2}\left(\Delta_{1}+\Delta_{2}+\Delta_{3}+\Delta_{4}\right) \frac{\sqrt{a^{2}+b^{2}}}{a b}$



Figure 8. Shear Distortion in the Panel Zone

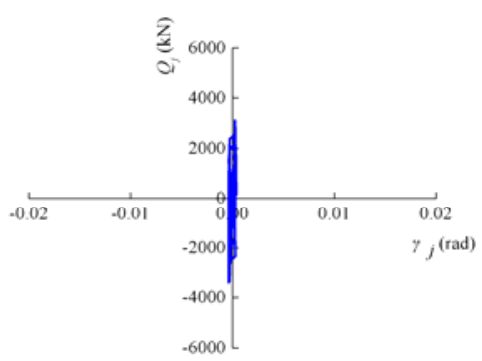

(a) Specimen JD-1

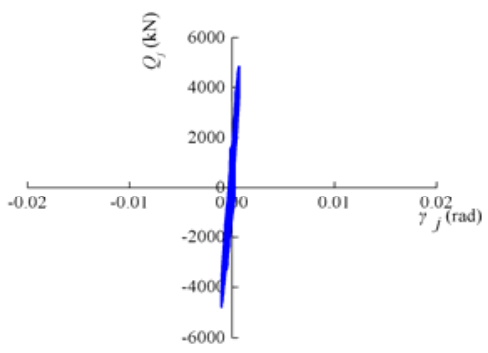

(c) Specimen JD-3



(b) Specimen JD-2

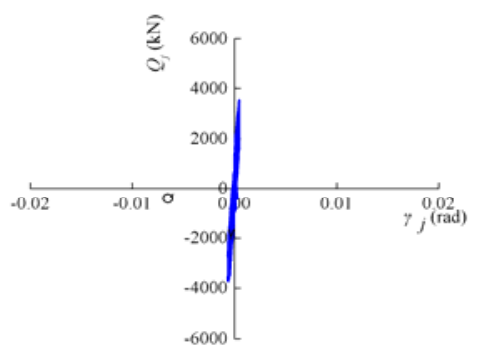

(d) Specimen JD-4

Figure 9. $Q_{j}-\gamma_{j}$ Curves

The hysteresis curves of all the specimens are almost linear, which demonstrated that the panel zone of connections is still in the elastic range. The maximum shear distortions of the specimens are less than $8 \times 10^{-4}$ rad. Consequently, it can be concluded that all the specimens have strong panel zone and the energy absorbed is largely attributed to the components surrounding the panel zone. 
The shear stiffness of these four connections was found to range from 6,639,545 kN/rad (Specimen JD-1) to 7,532,542 $\mathrm{kN} / \mathrm{rad}$ (Specimen JD-4), where the $11 \%$ and $13 \%$ increase in stiffness in Specimen JD-3 and JD-4, respectively, is associated with the addition of the horizontal stiffeners to the through-diaphragm connection detail. The tapered through-diaphragm connection detail (Specimen JD-2) had a 12\% greater stiffness than Specimen JD-1. Therefore, it indicates that the connection detail provided a comparable stiffness to that of the traditional through-diaphragm connection for steel beams-to-CFRT columns.

\subsection{Deformation Analysis}

When the specimens are subjected to lateral cyclic loading, the deformation of the connections is based on the contribution of the CFRT columns, the steel beam, and the panel zone. As shown in Figure 10, the displacement at the top of the column $\Delta$ is the summation of the displacement caused by the column $\left(\triangle_{c}\right)$, the beam $\left(\triangle_{b}\right)$, and the panel zone $\left(\triangle_{j}\right)$. Faella and Rizzano [40] pointed out that from the theoretical point of view, the rotation of beams and panel zones is of concern in the case of through-diaphragm connections, because in this case, yielding occurs at the member ends.
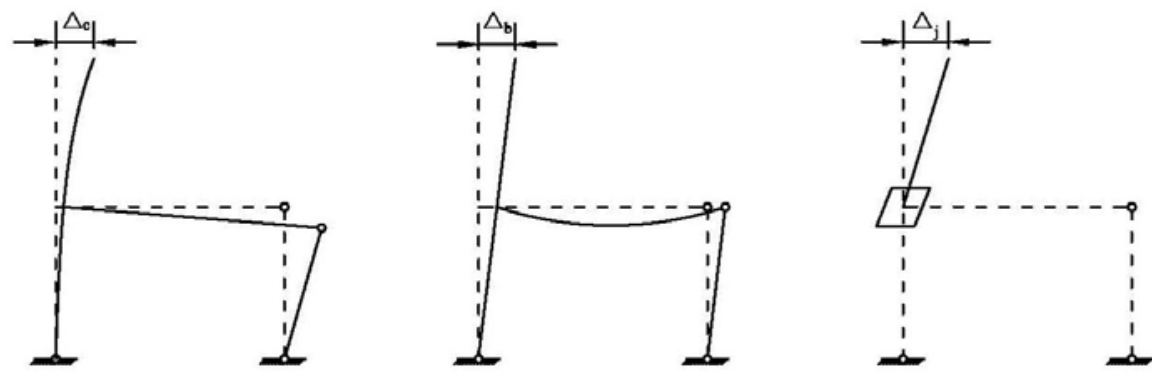

Figure 10. Deformation Analysis of An Exterior Connection

As shown in Figure 6, $\Delta$ is measured by transducer 1 and $2 ; \triangle_{j}$ is obtained by transducer 5 and 6; The total displacement of beam end and panel zone $\triangle_{b j}$ is determined by transducer 3 and 4 . Thus, $\triangle_{b}$ can be calculated by Eq. 2 . Another two transducers were installed at the bottom of the box foundations to obtain the displacement there. The deformation analysis results are shown in Figure 11, where $r_{\Delta j}=\Delta_{j} / \Delta, r_{\Delta b}=\Delta_{b} / \Delta$.

$$
\Delta_{b}=\Delta_{b j}-\Delta_{j}
$$

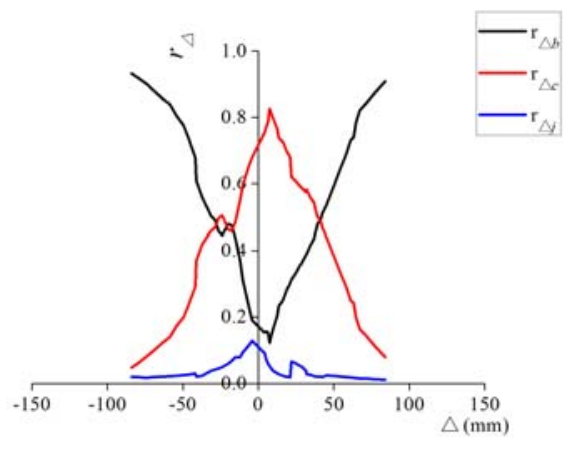

(a) Specimen JD-1

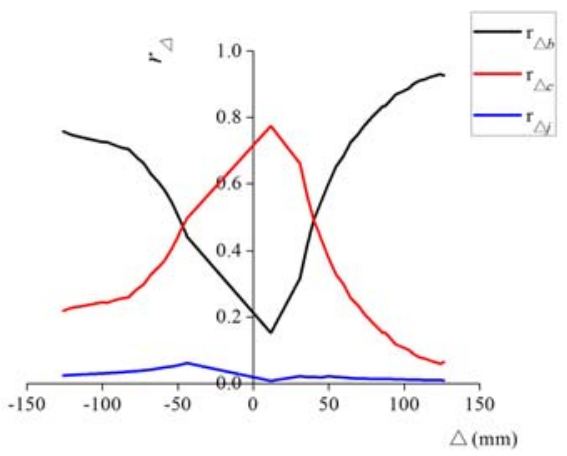

(b) Specimen JD-2 


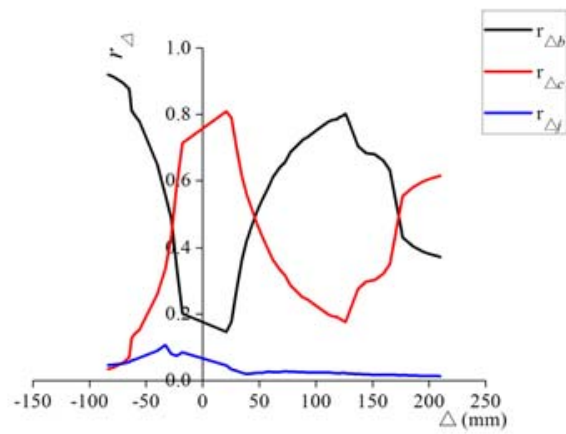

(a) Specimen JD-3

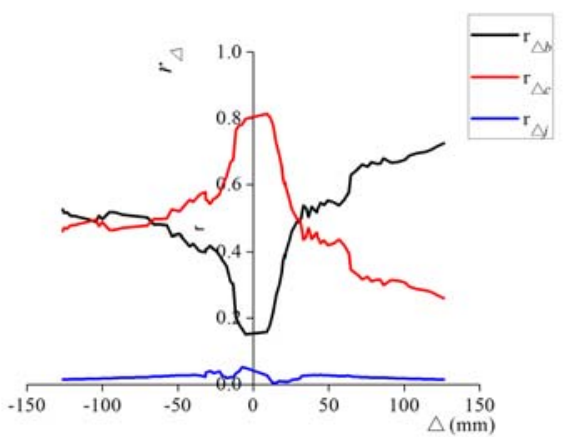

(b) Specimen JD-4

Figure 11. $r_{\Delta}-\Delta$ Curves

The displacement induced by the deformation of panel zone is the smallest. During the test, the shear deformation of the panel zone developed insufficiently and the value of $\triangle_{j}$ remained at an extremely low level. In general, the displacement caused by beam end grew larger with the continuing loading process. At the end of the test, the ratio of $\triangle_{b}$ to $\triangle$ exceeded $80 \%$ in most cases.

\section{STRAIN DISTRIBUTIONS}

Strain gauges were used to monitor the strains in the beam, through-diaphragm, and steel tube. Placement of the beam strain gauges was mainly concentrated in the beam closer to the connection. All readings were recorded using a computer. The layout of the strain gauges is illustrated in Figure 3. During the test, the strain distribution of Specimen JD-4 was similar to that of Specimen JD-3. Thus, for ease of presentation, only the strains of Specimen JD-1, JD-2 and JD-3 are discussed below.

\subsection{Strains of Specimen JD-1}

The distribution of the strains in the beam flange along the transverse direction are shown in Figure 12(a)-(e). The yield strain of the beam is $1740 \mu \varepsilon$. The test results showed that except for the strains near the complete joint penetration weld, the strains were uniformly distributed along the width of beam flange until the failure occurred. However, it was determined from Figure 12(b) that a non-uniform strain distribution developed across the width of the beam flange adjacent to the groove weld when the story drift angle exceeded $1.0 \% \mathrm{rad}$, and the value of strain at the side of beam flange was larger than that in the center. This is because the weld access hole there reduces the beam web section, which provides a weaker support to the center of flange of the beam and induces more force transferred through the sides of beam flange. Meanwhile, the strain in the center of the through-diaphragm was greater than that at the side. This phenomenon illustrates that the force from the beam flange did not sufficiently transfer to the part of column wall far away from the center.

Figure 12(f) shows the response of the strains in the beam flange along the longitudinal direction. It should be noted that the strains decreased steadily as the distance between the measured location and column face increased; the through-diaphragm and the end of the beam flange started to yield when the story drift angle was greater than $0.75 \%$. Additionally, there is a significant increase in the strain at the location between the beam flange and the through-diaphragm because the abrupt cross-section change there results in strain concentration. 
Figure 12(g)-(k) illustrate the strains of the beam web, where the positive values denote tensile strains, while the negative values denote compressive strains. The behavior was plotted at the point of each story drift. It demonstrates that the strains were linearly distributed over the section of the beam when the story drift angle was less than $1.0 \%$ rad. However, the distribution of strains over the section at a distance $20 \mathrm{~mm}$ and $200 \mathrm{~mm}$ away from the column face became non-linear when the story drift angle was greater than $1.0 \%$ rad, which indicates yielding began to develop in the web. This can also be seen from the slope change on moment-rotation curve.

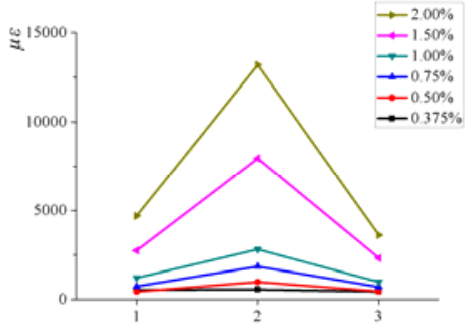

(a) Strain gauge No. 1-3

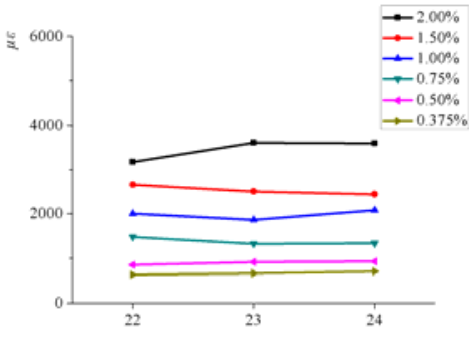

(c) Strain gauge No. 22-24

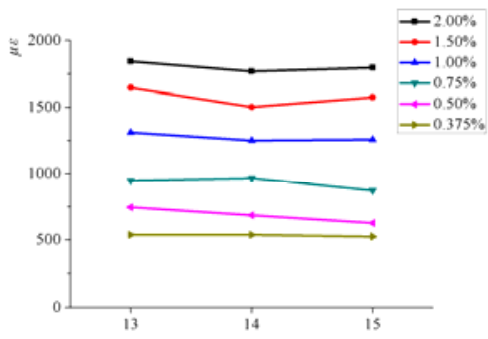

(e) Strain gauge No. 13-15

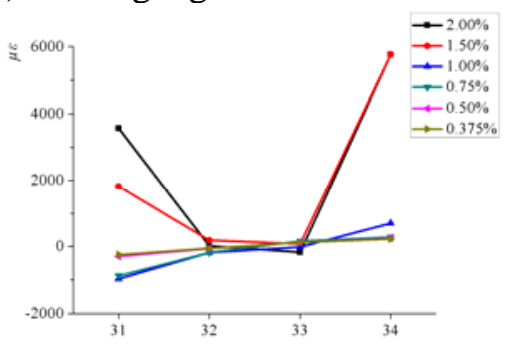

(g) Strain gauge No. 31-34

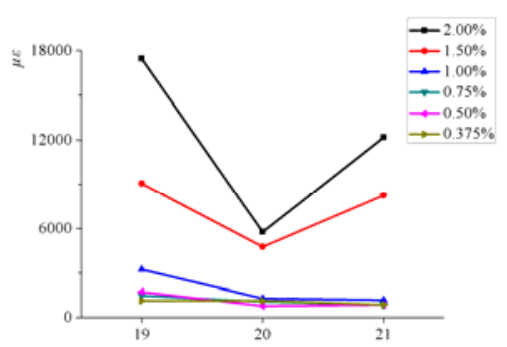

(b) Strain gauge No. 19-21

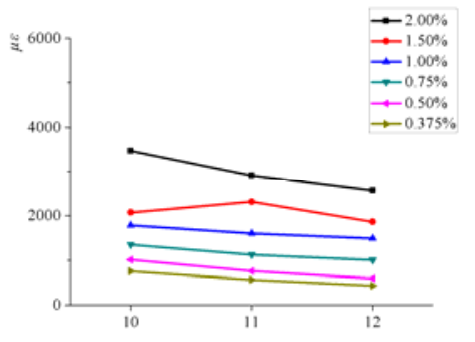

(d) Strain gauge No. 10-12

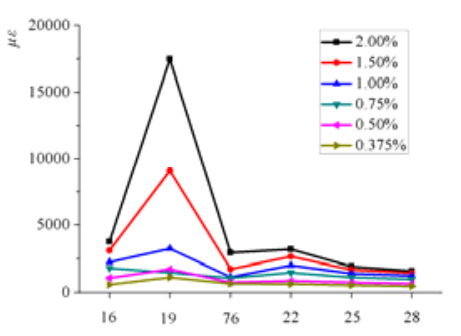

(f) Strain gauge No. 16,19,76,22,25,28

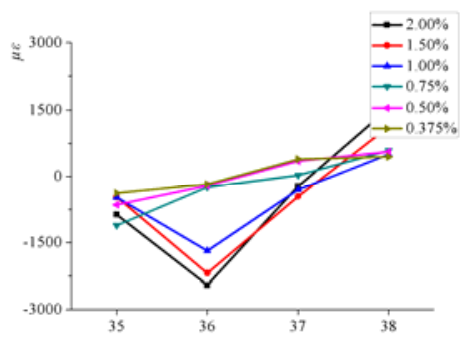

(h) Strain gauge No. 35-38 


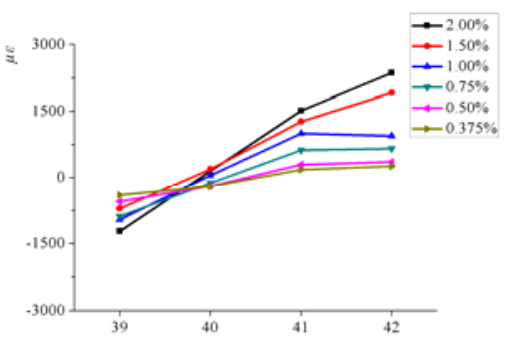

(i) Strain gauge No. 39-42

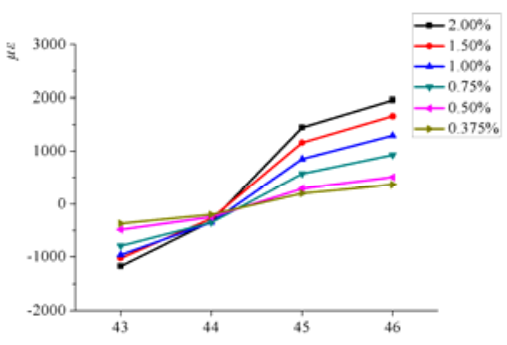

(j) Strain gauge No. 43-46

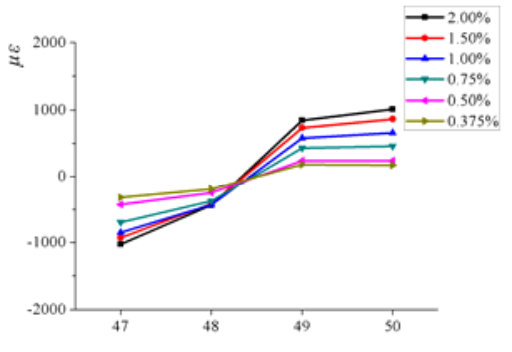

(k) Strain gauge No. 47-50

Figure 12. Strain Distribution of Specimen JD-1

\subsection{Strains of Specimen JD-2}

The strain distribution of Specimen JD-2 across the beam's flange shows a very consistent and similar behavior to that of Specimen JD-1, as shown in Figure 13(a)-(e). The cross-section strains were uniformly distributed until the story drift angle arrived at 3.0\%. However, the distribution of strains became non-uniform when the story drift angle exceeded 3.0\% rad. Compared to Specimen JD-1, the distribution of strains of Specimen JD-2 in the through-diaphragm near the column face shows different results. The strain level at the side was obviously higher than that in the center. This can be explained by the fact that the tapered through-diaphragm helps the force transfer to a larger part of column tube.

The strain distribution in the beam flange along the beam length is illustrated in Figure 12(f). It can be seen that the tapered diaphragm provides a more gradual transition in the force transfer path, although the strain concentration still developed at the location between the beam and the diaphragm.

The strain distribution shown in Figure 12(g)-(j) indicate that yielding began to develop at a distance $150 \mathrm{~mm}$ away from the column tube face. As the test progressed, the beam web had yield for a distance of up to $350 \mathrm{~mm}$ before the connection failed. The same figure also shows that the maximum strain located $700 \mathrm{~mm}$ from column face is almost equal to the yield strain at the ultimate load. This result implies that this tapered plates connection detail significantly helps move the plastic hinge away from the column and the length of yielded region was less than the depth of beam. 


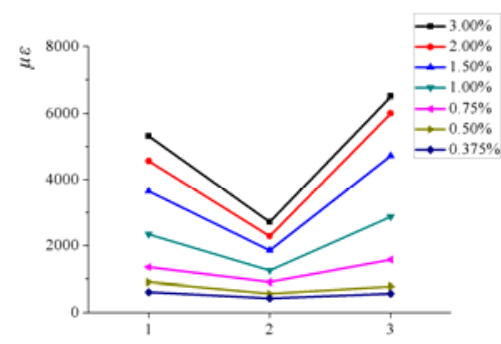

(a) Strain gauge No. 1-3

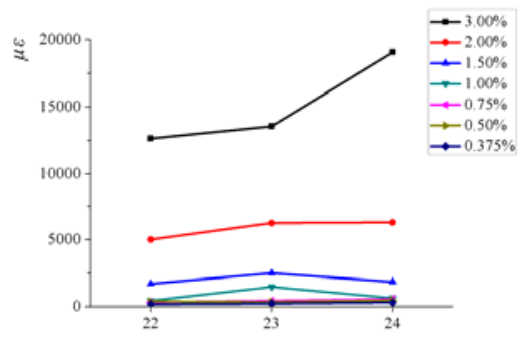

(c) Strain gauge No. 22-24

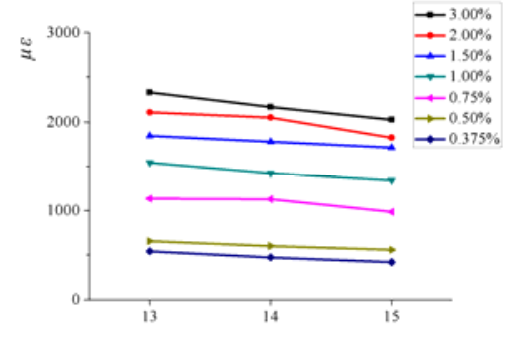

(e) Strain gauge No. 13-15

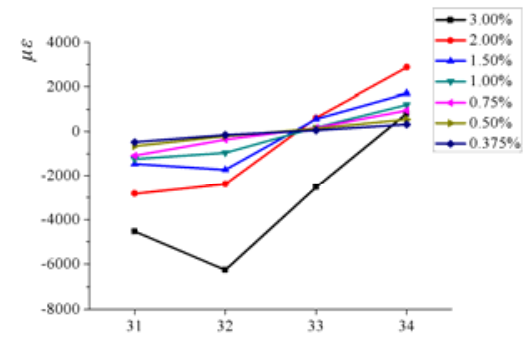

(g) Strain gauge No. 31-34

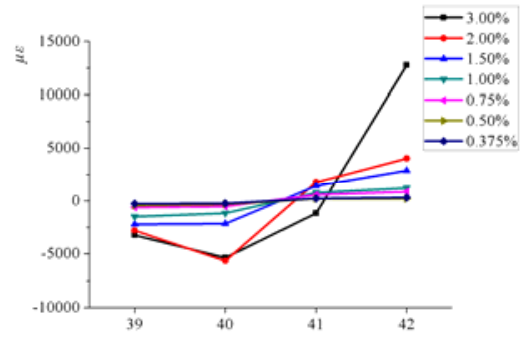

(i) Strain gauge No. 39-42

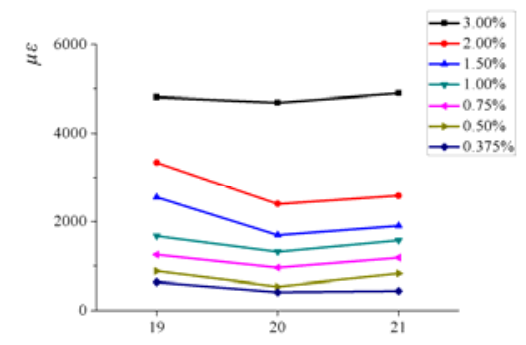

(b) Strain gauge No. 19-21

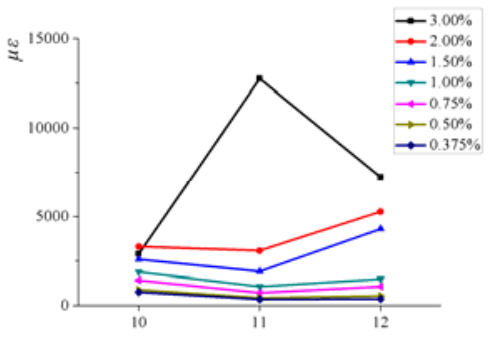

(d) Strain gauge No. 10-12

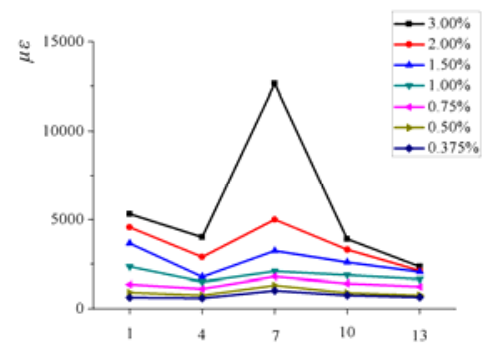

(f) Strain gauge No. 1,4,7,10,13

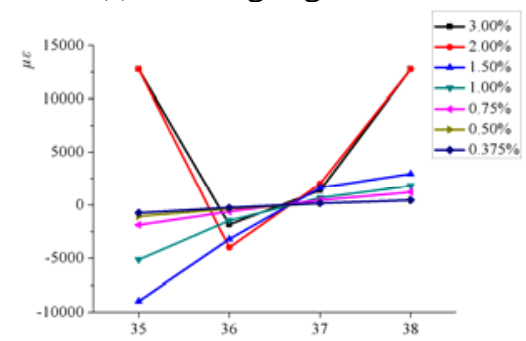

(h) Strain gauge No. 35-38

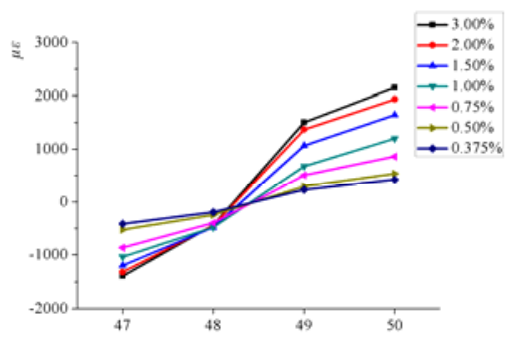

(j) Strain gauge No. 47-50

Figure 13. Strain Distribution of Specimen JD-2 


\subsection{Strains of Specimen JD-3}

Figure 14(a)-(f) show the typical strain profile measured across the width of beam flange at different positions along its span, illustrating the different behavior which occurred. It is worth noting the more evident change in the strain distribution as the cross-section is closer to the connection, mainly attributed to the more extensive inelastic yielding of the steel beam. An examination of the strains of the beam flange in the fractured area indicates that a significant amount of strain had developed there. Reading from strain gauges located near the crack revealed a strain had developed that exceeded 14,000 microstrain before fracture occurred. Strain gauge readings revealed that a shear lag phenomenon developed along the width of through-diaphragm, where the longitudinal strain was relatively larger in the location adjacent to the horizontal stiffener. This indicates that a significant amount of the beam's flange force was transferred from the triangle plates to the sides of the steel tube that formed the connection's panel zone.

Figure 14(g) illustrates response of the bottom flange strains along the longitudinal direction. The strains were measured at the distance of $0 \mathrm{~mm}, 120 \mathrm{~mm}, 235 \mathrm{~mm}, 350 \mathrm{~mm}, 650 \mathrm{~mm}$, and $950 \mathrm{~mm}$, respectively, from the column face. The specimen had less strain at both sides than it did in the center of the beam. It is attributed to the effort of tapered plates which shares a large amount of force transferred through the sides of the beam flange. It should be noted that the maximum strain of the top and bottom flanges for Specimen JD-3 was obviously less than that in Specimen JD-1, which implied that the triangular plates can affect the strain distribution of the beam.

The web strain response of Specimen JD-3 is shown in Figure 14(h)-(k). The yielding first developed at the region $120 \mathrm{~mm}$ from the column face, which is expected since the its access hole had a $300 \mathrm{~mm}$ longitudinal cut deep in the web of the beam, and the reduced web section of the beam force most of the deformation occurring within this region.

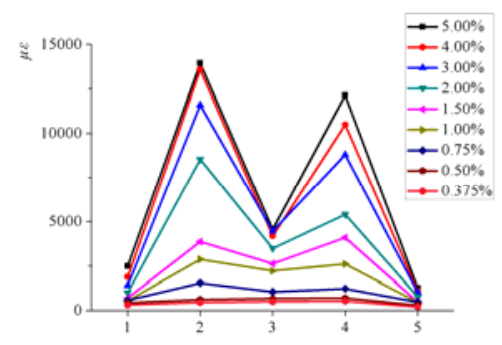

(a) Strain gauge No. 1-5

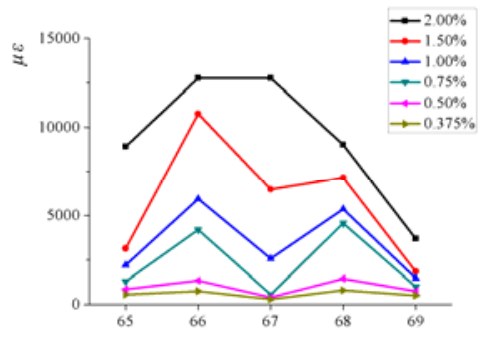

(c) Strain gauge No. 65-69



(b) Strain gauge No. 60-64



(d) Strain gauge No. 75-79 


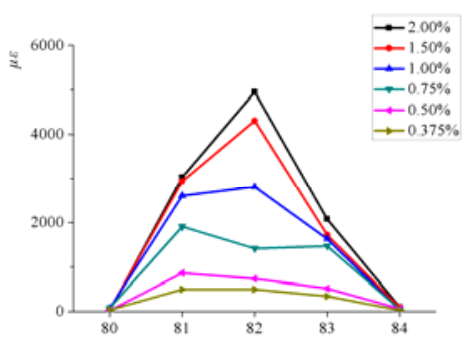

(e) Strain gauge No. 80-84

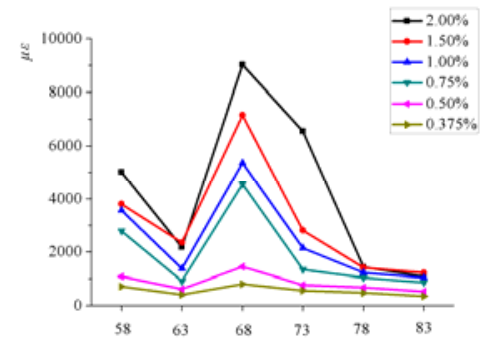

(g) Strain gauge No. 58,63,68,73,78,83



(i) Strain gauge No. 46-48

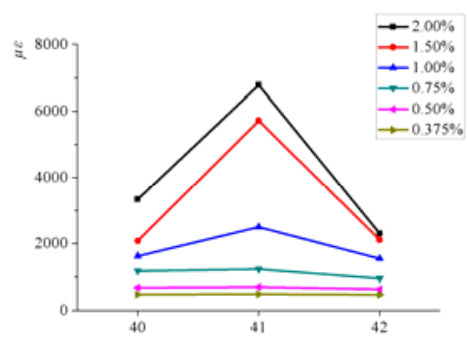

(f) Strain gauge No. 40-42

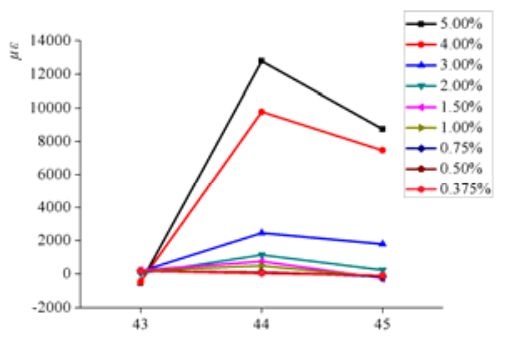

(h) Strain gauge No. 43-45

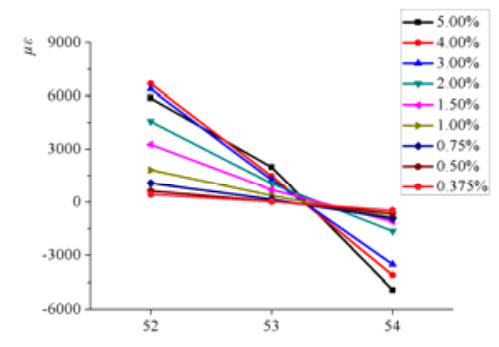

(k) Strain gauge No. 52-54

Figure 14. Strain Distribution of Specimen JD-3

\subsection{Key Findings}

Comparison of strain distribution among four connections indicates that, it is evident that the behavior in the beam strain was considerably influenced by the variation in the connection details, as illustrated by results of Specimen JD-1, JD-2, and JD-3.

In the figure, it can be observed that both the web and flanges of the beams near the connections in all specimens had far exceeded the yield strain. The traditional through-diaphragm connection (Specimen JD-1) appeared to be the highest stressed at both the diaphragm and the beam flange at the same load level. This phenomenon demonstrates that providing improvement to connection configuration guarantees an increase in rotation capacity and a significantly higher strength 
capacity. Moreover, the connection details have a significant influence on the position of the plastic hinge and determine whether or not the force can be sufficiently delivered from the steel beam to the CFRT column.

Meanwhile, Specimen JD-3 had the highest strain values in the web, which is reasonable since the deep longitudinal cut in the web results in the stress concentration there. This is also the region that was designed to absorb the seismic energy and thus, provide a ductile behavior of the through-diaphragm connection.

\section{SUMMARY AND CONCLUSIONS}

In this paper, an experimental program comprising four through-diaphragm connections subjected to cyclic load was conducted, and the relationship of lateral force versus beam-column rotation, shear force versus shear distortion curves, deformation, and strain distribution were analyzed. The main conclusions can be drawn as follows:

(1) The lateral force versus beam-column rotation response of the proposed connections was obviously enhanced when compared to the traditional connection, attributed to the improved geometrical detail of the connection. This indicates that seismic resistance of the proposed connections is much better than the existing one. As a result, the proposed types are more suitable for application in moment resisting frames in seismic regions.

(2) The stiffness of the proposed connections is higher than that of the traditional one. Therefore, the beneficial effect of the elements surrounding the panel zone should be taken into account to calculate the shear stiffness.

(3) The deformation of the beam end is the largest contribution to the total displacement of the connection. This demonstrates that more yielding occurred there.

(4) The connection details clearly affect the load path how the force is transferred from the beams to the columns. Additionally, the proposed types significantly alleviate the stress concentration in the beam flange and evidently enhance the ductility of the traditional connection.

\section{ACKNOWLEDGEMENTS}

This work is sponsored by the National Natural Science Foundation of China (Grant No. NSFC61272264), the twelfth five-year national science and technology support program (Grant No. 2011BAJ08B02-04) and key project in the Tianjin Science \& Technology Pillar Program (Grant No. 11ZCGYSF01000). The authors would like to thank the Zhejiang Hangxiao Steel Structure Co. Ltd. for the supply of test specimens, the Architecture Design Co. Ltd of Tadi for technical support on the specimen design, Wan Fanggui of Tianjin University and Wang Hailiang, Yang Xinlei, Ren Quancang, Bao Quanli, Jin Cheng, Wang Zhenyu of Tianjin Chengjian University for their assistance with the laboratory work. The authors also appreciate the financial support provided by the Chinese Scholarship Council (File No. 201206250067) that enables the Visiting Research Scholar to cooperate with Dr. Benjamin W. Schafer at Johns Hopkins University at Baltimore. 


\section{REFERENCES}

[1] Kang, C.H., Shin, K.J., Oh, Y.S. and Moon, T.S., "Hysteresis Behavior of CFT Column to H-beam Connections with External T-stiffeners and Penetrated Elements”, Engineering Structures, 2001, Vol. 23, No. 9, pp. 1194-1201.

[2] Varma, A.H., Ricles, J.M., Sause, R. and Lu, L.W., "Seismic Behavior and Modeling of High-strength Composite Concrete-filled Steel Tube (CFT) Beam-columns”, Journal of Constructional Steel Research, 2002, Vol. 58, No. 5-8, pp. 725-758.

[3] Ricles, J.M., Peng, S.W. and Lu, L.W., "Seismic Behavior of Composite Concrete Filled Steel Tube Column-wide Flange Beam Moment Connections”, Journal of Structural Engineering, 2004, Vol. 130, No. 2, pp. 223-232.

[4] Shin, K.J., Kim, Y.J., Oh, Y.S. and Moon, T.S., "Behavior of Welded CFT Column to H-beam Connections with External Stiffeners”, Engineering Structures, 2004, Vol. 26, No. 13, pp. 1877-1887.

[5] Cheng, C.T., Chan, C.F. and Chung, L.L., "Seismic Behavior of Steel Beams and CFT Column Moment-resisting Connections with Floor Slabs”, Journal of Constructional Steel Research, 2007, Vol. 63, No. 11, pp. 1479-1493.

[6] Wu, L.Y., Chung, L.L., Tsai, S.F., Lu, C.F. and Huang, G.L., "Seismic Behavior of Bidirectional Bolted Connections for CFT Columns and H-beams”, Engineering Structures, 2007, Vol. 29, No. 3, pp. 395-407.

[7] Nie, J.G., Qin, K. and Cai, C.S., "Seismic Behavior of Connections Composed of CFSSTCs and Steel-concrete Composite Beams-Experimental Study”, Journal of Constructional Steel Research, 2008, Vol. 64, No. 10, pp. 1178-1191.

[8] Wang, W.D., Han, L.H. and Zhao, X.L., "Analytical Behavior of Frames with Steel Beams to Concrete-filled Steel Tubular Column”, Journal of Constructional Steel Research, 2009, Vol. 65, No. 3, pp. 497-508.

[9] Park, S.H., Choi, S.M., Kim, Y.S., Park, Y.W. and Kim, J.H., "Hysteresis Behavior of Concrete Filled Square Steel Tube Column-to-beam Partially Restrained Composite Connections”, Journal of Constructional Steel Research, 2010, Vol. 66, No. 7, pp. 943-953.

[10] Qin, Y., Chen, Z., Yang, Q. and Shang, K., "Experimental Seismic Behavior of Through-Diaphragm Connections To Concrete-Filled Rectangular Steel Tubular Columns”, Journal of Constructional Steel Research, 2014, Vol. 93, pp. 32-43.

http://dx.doi.org/10.1016/j.jcsr.2013.10.020

[11] Qin, Y., Chen, Z. and Wang, X., "Experimental Investigation of New Internal-Diaphragm Connections to CFT Columns Under Cyclic Loading”, Journal of Constructional Steel Research, 2014, Vol. 98, pp. 35-44. http://dx.doi.org/10.1016/j.jcsr.2014.02.014

[12] Kawano, A., Matsui, C. and Murai, N., "Load-deformation Relationship Models for Local Deformations in Diaphragm-stiffened Connections of H-shaped Steel Beams to Rectangular CFT Columns”, Steel Construction Engineering, 1998, Vol. 5, No. 17, pp. 93-104.

[13] Koester, B.D., "Panel Zone Behavior of Moment Connections between Rectangular Concrete-filled Steel Tubes and Wide Flange Beams”, Ph.D. thesis, The University of Texas at Austin, Austin, 2000.[14] Lu, X.L., Yu, Y., Kiyoshi, T. and Satoshi, S., "Experimental Study on the Seismic Behavior in the Connection between CFRT Column and Steel Beam”, Structural Engineering and Mechanics, 2000, Vol. 9, No. 4, pp. 365-374.

[15] Morino, S. and Tsuda, K., "Design and Construction of Concrete-filled Steel Tube Column System in Japan”, Earthquake Engineering and Engineering Seismology, 2002, Vol. 4, No. 1, pp. 51-73.

[16] Fukumoto, T. and Morita, K., "Elastoplastic Behavior of Panel Zone in Steel Beam-to-concrete Filled Steel Tube Column Moment Connections”, Journal of Structural Engineering, 2005, Vol. 131, No. 12, pp. 1841-1853. 
[17] Park, J.W., Kang, S.M. and Yang, S.C., "Experimental Studies of Wide Flange Beam to Square Concrete-filled Tube Column Joints with Stiffening Plates Around the Column”, Journal of Structural Engineering, 2005, Vol. 131, No. 12, pp.1866-1876.

[18] Jiang, X.L., Miao, J.K. and Chen, Z.H., "Experiment on Seismic Performance of Diaphragm-through Joint between Concrete-filled Square Steel Tubular Column and Steel Beam”, Journal of Tianjin University, 2009, Vol. 42, No. 3, pp. 194-200.

[19] Nie, J.G., Qin, K. and Cai, C.S., "Seismic Behavior of Composite Connections - Flexural Capacity Analysis”, Journal of Constructional Steel Research, 2009, Vol. 65, No. 5, pp. 1112-1120.

[20] Rong, B., Chen, Z.H., Zhang, R.Y., Apostolos, F. and Yang, N., "Experimental and Analytical Investigation of the Behavior of Diaphragm-through Joints of Concrete-filled Tubular Columns”, Journal of Mechanics of Materials and Structures, 2012, Vol. 7, No. 10, pp. 909-929.

[21] Qin, Y., Chen, Z. and Wang, X., "Elastoplastic Behavior of Through-Diaphragm Connections to Concrete-Filled Rectangular Steel Tubular Columns”, Journal of Constructional Steel Research, 2014, Vol. 93, pp. 88-96.

http://dx.doi.org/10.1016/j.jcsr.2013.10.011

[22] Qin, Y., Chen, Z. and Rong, B., “Component-Based Mechanical Models for Axially-Loaded Through-Diaphragm Connections to Concrete-Filled RHS Columns”, Journal of Constructional Steel Research, 2014, Vol. 102. [in press] http://dx.doi.org/10.1016/10.1016/j.jcsr.2014.06.016

[23] Qin, Y., Chen, Z. and Han, N., "Research On Design of Through-Diaphragm Connections Between CFRT Columns and HSS Beams”, International Journal of Steel Structures, 2014. [in press]

[24] Loh, H.Y., Uy, B. and Bradford, M.A., "The Effects of Partial Shear Connection in Composite Flush End Plate Joints Part I - Experimental Study”, Journal of Constructional Steel Research, 2006, Vol. 62, No. 4, pp. 378-390.

[25] Wang, J.F., Han, L.H. and Uy, B., "Behaviour of Flush End Plate Joints to Concrete-filled Steel Tubular Columns”, Journal of Constructional Steel Research, 2009, Vol. 65, No. 4, pp. 925-939.

[26] Tizani, W., Wang, Z.Y. and Hajirasouliha, I., "Hysteretic Performance of a New Blind Bolted Connection to Concrete Filled Columns under Cyclic Loading: An Experimental Investigation”, Engineering Structures, 2013, Vol. 46, pp. 535-546.

[27] Málaga-Chuquitaype, C. and Elghazouli, A.Y., "Behaviour of Combined Channel/Angle Connections to Tubular Columns under Monotonic and Cyclic Loading”, Engineering Structures, 2010, Vol. 32, No. 6, pp. 1600-1616.

[28] Wu, L.Y., Chung, L.L., Tsai, S.F., Shen, T.J. and Huang, G.L., "Seismic Behavior of Bolted Beam-to-column Connections for Concrete Filled Steel Tube”, Journal of Constructional Steel Research, 2005, Vol. 61, No. 10, pp. 1387-1410.

[29] Tort, C. and Hajjar, J.F., "Capacity Assessment of Rectangular Concrete-filled Steel Tube (RCFT) Members and Connections for Performance-based Design of Composite Frames”, Structures Congress 2005, New York, United States, April 20-24, 2005.

[30] Zhao, H.L., Kunnath, S.K. and Yuan Y., "Simplified Nonlinear Response Simulation of Composite Steel-concrete Beams and CFST Columns”, Engineering Structures, 2010, Vol. 32, No. 9, pp. 2825-2831.

[31] Choi, Y.H., Routch, D.A. and LaFave, J.M., "New Approach to AISC P-M Interaction Curve for Square Concrete Filled Tube (CFT) Beam-columns”, Engineering Structures, 2006, Vol. 28, No. 11, pp. 1586-1598.

[32] Shams, M. and Saadeghvaziri, M.A., "State of the Art of Concrete-filled Steel Tubular Columns”, ACI Structural Journal, 1997, Vol. 94, No. 5, pp. 558-571. 
[33] Shanmugam, N.E. and Lakshmi, B., "State of the Art Report on Steel-concrete Composite Columns”, Journal of Constructional Steel Research, 2001, Vol. 57, No. 10, pp. 1041-1080.

[34] Nishiyama, I., Morino, S., Sakino, K. et al., "Summary of Research on Concrete-filled Structural Steel Tube Column System Carried Out under the US-Japan Cooperative Research Program on Composite and Hybrid Structures”, BRI Research Paper No.147, Japan: Building Research Institute, 2002.

[35] Kurobane, Y., Packer, J.A., Wardenier, J. and Yeomans, N., "Design Guideline for Structural Hollow Section Column Connections”, Germany, 2004.

[36] Chen, Z., Qin, Y. and Wang, X., "Development of Connections to Concrete-Filled Rectangular Tubular Columns”, Advanced Steel Construction, 2014. [in press]

[37] Fukumoto, T., "Steel-beam-to-concrete-filled-steel-tube-column Moment Connections in Japan”, Steel Structures, 2005, Vol. 5, No. 4, pp. 357-365.

[38] Choi, S., Lee, S., Hong, S. and Kim, J., "Structural Capacities of Tension Side for CFT Square Column-to-beam Connections with Combined-cross Diaphragm”, Advances in Structural Engineering, 2008, Vol. 11, No. 2, pp. 209-227.

[39] You, J., Chen, G. and Han, L., "Preliminary Discussion on Dimension of Ring of Concrete-filled Steel Tube Column Joint with External Ring”, Journal of Harbin Institute of Technology, 2005, Vol. 37, pp. 354-357.

[40] ANSI/AISC 341-10, “Seismic Provisions for Structural Steel Buildings”, Chicago (IL), 2010.

[41] Faella, C. and Rizzano, G., "Structural Steel Semirigid Connections: Theory, Design and Software”, Fla (Boca Raton): CRC Press, 2000. 